\title{
Vitamin A content of fortified maize meal and porridge as purchased and consumed in South Africa
}

\author{
${ }^{1}$ Beulah Pretorius \& ${ }^{2}$ Hettie C Schönfeldt \\ ${ }^{1}$ Agricultural Research Council, Private Bag X2, Irene, South Africa. E-mail: \\ beulah@arc.agric.za. Tel: +27 12672 9244, Fax: +27 126651605 \\ ${ }^{2}$ School of Agricultural and Food Science, University of Pretoria, Pretoria, South Africa. E- \\ mail: hettie.schonfeldt@up.ac.za
}

\begin{abstract}
In 2003 the Department of Health of South Africa embarked on a mandatory fortification programme of maize meal as part of a nutrition program to alleviate malnutrition. The aim of this study was to determine the vitamin A content in fortified white maize meal and the maize porridge prepared with it as purchased and consumed. The highest mean vitamin A concentration in the maize meal was $261 \mu \mathrm{gRE} / 100 \mathrm{~g}$ and the lowest mean vitamin $\mathrm{A}$ concentration was $<19 \mu \mathrm{gRE} / 100 \mathrm{~g}$. Pertaining to regulation the final minimum level of vitamin $A$ in fortified maize meal shall not be less than $187.7 \mu \mathrm{g} / 100 \mathrm{~g}$ (Foodstuffs, Cosmetics and Disinfectants Act, 2003). The average retention of vitamin A in maize porridge as the difference in vitamin A concentration between raw maize meal and cooked porridge was calculated as $39.8 \%$. Although fortification of maize meal can improve the vitamin A intake of the population, it must be regularly monitored and regulate in order to be beneficial. If not then fortification might as well be voluntary.
\end{abstract}

Key words: maize meal, porridge, vitamin A fortification, retention, staple foods ${ }^{1}$ Corresponding author 
1. Introduction

Food fortification of staple foods with micronutrients is one of the food based strategies employed to alleviate micronutrient deficiencies in a population. Vitamin A deficiency (VAD) is a major nutritional concern in poor societies, especially in lower income countries. Its presence as a public health problem is assessed by measuring the prevalence of deficiency in a population, represented by specific biochemical and clinical indicators of status (WHO, 2009a). In South Africa, 1 in 3 preschool children has a serum retinol concentration $<0.7 \mu \mathrm{mol} / \mathrm{L}$ (SAVACG, 1996), and 55-68\% of children aged $1-9$ years consume $<50 \%$ of the recommended dietary intake of vitamin A $(700 \mu \mathrm{g}$ retinol equivalents) (NFCS, 2000). The main underlying cause of VAD as a public health problem is a diet that is chronically insufficient in bioavailable vitamin A that can lead to lower body stores and fail to meet physiologic needs (e.g. support tissue growth, normal metabolism, resistance to infection) (WHO, 2009a). In 2003, the Department of Health of South Africa embarked on a fortification programme of wheat flour and white maize meal as part of a multipronged approach to alleviate malnutrition. These foods were identified during the National Food Consumption Survey (NFCS, 2000) as most often consumed (staple) food products, thereby reaching lower income consumers most vulnerable to micronutrient malnutrition. According to regulations protected, stabilized Vitamin A palmitate containing 75000 mcg RE activity per gram premix must be added to the maize meal (special, super, sifted and unsifted) to give a final, minimum level of the micronutrient in the fortified maize meal at 187.7 mcg RE activity per $100 \mathrm{~g}$ (Foodstuffs, Cosmetics and Disinfectants Act, 2003).

The success of a fortification program depends upon, amongst others, on the 
content of the fortificants in the fortified products. A number of factors, including nutrient interactions, the stability of the specific micronutrients added to the food under anticipated conditions of storage and processing can all have an influence on the fortificant concentration. The choice of a vitamin A fortificant is largely governed by the characteristics of the food vehicle. As preformed vitamin $A$ (retinol) is an unstable compound, in commercial preparations it is esterified, usually with palmitic or acetic acid, to the more stable corresponding esters. Retinyl acetate and retinyl palmitate are the main commercial forms of vitamin $A$ that are available for use as food fortificants in cereals (WHO, 2006). Maize meal can technically be fortified with vitamin $A$ as vitamin $A$ is stable in dry products without producing organoleptic changes. Vitamin A is quite stable when heated to moderate temperatures in the absence of oxygen and light. However, as is the case for some other vitamins, high humidity, high temperatures and the presence of oxygen and light can adversely affect the vitamin A content during the preparation of maize meal products such as traditional maize porridge (or "pap"). This reaction is also accelerated in the presence of trace metals (Mehansho et al., 2003; WHO, 2009b).

It would thus be feasible to add vitamin A to any kind of maize meal with the primary constraint being cost. Inclusion of an expensive micronutrient such as vitamin A can double or triple the cost of a cereal fortification program due to the cost of the micronutrient, extra equipment needed for mixing, quality control through quantitative vitamin analysis and additional personnel (WHO, 2009b).

An early quality control step to make sure that the food fortification program will have an impact on vitamin A deficiency is to verify the vitamin A content in the 
fortified maize meal as well as in the cooked products. If these comply with regulations, a reduction in vitamin A deficiency can be assumed in the long term.

Therefore the aim of this study was to determine the vitamin A content of fortified white maize meal from different manufacturers (brands) as purchased from the shelves of different retailers, as well as in the traditional maize porridge as consumed. Due to financial constraints and the fact that the vitamin A fortificant is stable under dry storage conditions (WHO, 2009b), a shelf-live study was not done.

\section{Materials and Methods}

Note: Light should be avoided during preparation and storage of samples and standards to prevent degradation of vitamin A.

\subsection{Samples}

Sixty-two samples of fortified white maize meal from readily available brands (nine different brands) were collected from supermarkets in the Tshwane-metropole between July 2005 and November 2008. Samples were stored in their original packaging at room temperature in the laboratory until analysis. Analyses commenced within a week after every sampling. Brands with a higher market share according to the Markinor/Sunday times Top Brands Results (2008) have higher representation within the data set. A wide variety of maize porridge preparation methods is known, but due to resource constrains only the traditional soft porridge was selected for laboratory simulation. The maize porridge was prepared according to a standardised method from seven different brands of maize meal purchased from the supermarkets. Each maize meal and 
corresponding porridge sample were analysed in duplicate for moisture and vitamin A content using accredited methods according to ISO/IEC 17025:2005. The accreditation body is the South African National Accreditation System (SANAS).

\subsection{Preparation of porridge samples}

Traditional soft maize porridge was prepared according to the following recipe: One litre (1L) of tap water was heated to boiling point in an aluminium saucepan. A $180 \mathrm{~g}$ sample of dry maize meal was added and stirred thoroughly. The heat was turned down and the porridge was left to simmer with the lid on for 30 minutes, whilst stirring every now and then. The end-temperature of the samples was between $75^{\circ} \mathrm{C}-80^{\circ} \mathrm{C}$. The samples were prepared with the assistance of people familiar with the preparation method, texture and consistency of this type of traditional porridge. Porridge samples were left to cool in covered glass containers and were stored in the fridge until the next day when it was analysed.

\subsection{Gravimetric determination of dry matter}

Dry matter was measured in the samples by determining the loss in weight of the sample after it has been dried in an oven at $105 \pm 1{ }^{\circ} \mathrm{C}$ for 16 hours. Weight loss is used to calculate dry matter content (AOAC, 2005a).

\subsection{Determination of total Vitamin A as all-trans retinol}

\subsubsection{Chemicals and Standards}

Diethyl ether, ethanol (99.9\%), potassium hydroxide $(\mathrm{KOH})$ and sodium chloride $(\mathrm{NaCl})$ were obtained from Merck Chemicals. Butylated hydroxyl toluene (BHT) and retinol standard were purchased from Sigma-Aldrich. HPLC-grade methanol 
was obtained from Labscan and pure, crystallised ascorbic acid from Associated Chemical Enterprises. A stock standard solution from retinol was prepared in ethanol. Working standard solutions were prepared in ethanol and the concentration of each standard were determined with a spectrophotometer (Lambda 25, PerkinElmer), using an extinction coefficient of $1850\left(\lambda_{\max }=325 \mathrm{~nm}\right)$.

\subsubsection{Sample preparation}

Approximately $5 \mathrm{~g}$ maize meal or $8 \mathrm{~g}$ porridge was weighed in a round bottom flask.

\subsubsection{Saponification}

The weighed sample was mixed with a $0.5 \%$ ascorbic acid-ethanol-methanol solution until sample material was moistened. Glass beads were added and purged with nitrogen gas. The sample was saponified at boiling point for $30 \mathrm{~min}$ under reflux with $50 \% \mathrm{KOH}(\mathrm{w} / \mathrm{w})$. The flask was swirled from time to time to prevent the material from adhering to the sides. After saponification the sample was cooled on ice for 5 minutes.

\subsubsection{Extraction and phase transfer}

The contents of the round bottom flask were filtered through Whatman no 4 filter paper into a separating funnel. The flask was rinsed with a minimum amount of water and filtered into the separating funnel. Subsequently the round bottom flask was washed with diethyl ether containing $0.01 \% \mathrm{BHT}$ and added to the separating funnel. The mixture was allowed to expand several times before the actual extraction (in such conditions emulsions can be largely avoided). The ether layer was decanted into another separating funnel. Extraction was repeated two more times combining all the ether fractions in the same separating funnel. The ether fraction was washed with distilled water until neutral. Should any emulsions form during the wash and extraction procedures, $\mathrm{NaCl}$ can be added. The ether fraction 
was then transferred to a volumetric flask and make up to volume with diethyl ether. An aliquot from the ether extract was evaporated to dryness with a rotary evaporator under partial vacuum in a water bath with temperature $<40^{\circ} \mathrm{C}$. The residue was dissolved in ethanol and injected into the HPLC.

\subsubsection{HPLC}

The HPLC system (Shimadzu) consisted of a Quaternary gradient pump (model LC-20AD), a solvent degasser (model DGU-20A5), an auto-injector (model SIL-20A, 230V), a Photodiode Array Detector (DAD) with a thermostatted standard cell (model SPD-M20A) and control and integration software

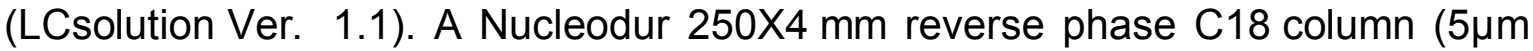
particle size) with guard column was used. Separations were achieved using a mobile phase of $97 \%$ methanol in deionised water and a flow rate of $1.0 \mathrm{~mL} / \mathrm{min}$. Separations was performed at $325 \mathrm{~nm}$ for the identification and quantification of retinol.

\subsubsection{Calculation}

Quantification was performed by using an external calibration procedure. The peak height of five different concentrations of a retinol standard and a blank (ethanol) were used for calibration. The calibration standards were checked for purity and concentration by spectrophotometric procedure.

\subsubsection{Method validation}

Retinol was determined by using peak height and regression analysis. From the calibration curve, linearity, range, limit of quantification (LOQ) and limit of detection (LOD) were determined. The LOQ and LOD were calculated from the calibration lines that defined linearity, using the Long and Winefordner criterion (Long and Winefordner, 1983) as expressed in the following equations. 


$$
\begin{aligned}
& L O Q=\frac{10 \times S}{a} \\
& L O D=\frac{3 \times S}{a}
\end{aligned}
$$

where $a$ is the slope of the calibration line and $S$ is the standard error of the intercepted point. The LOQ, LOD and precision of the method is shown in table 1.

Repeatability of the method was determined by analysing the same sample eight times on the same day. From this data the mean, standard deviation (SD) and coefficient of variation (CV\%) were determined. Reproducibility of the method was determined by analysing a control sample (infant cereal with added vitamins) over a period of time ( $\geq 7$ times). The mean, standard deviation and coefficient of variation were calculated. A control chart was implemented to monitor validity of the analysis. The action limits were set as the mean plus or minus three times the standard deviation of the reproducibility data. Warning limits were set as twice the standard deviation. The control sample (infant cereal) was analysed with every batch of ten samples or less. The results of the control sample were recorded on the control chart and evaluated. If the result falls outside the action limits, the analysis was repeated. Standard reference material (SRM2383 - baby food composite) and inter-laboratory comparisons (using fortified maize meal as a control sample) were used to proof accuracy.

\subsection{Calculation of the retention of vitamin A in porridge}

Retention of vitamin A was calculated based on the following equation (Bengtsson, Namutebi, Alminger, and Svanberg, 2008):

$$
\% \text { Retention }=\frac{\text { retinol content per } g \text { porridge }(\text { dry basis })}{\text { retinol content per } g \text { meal }(\text { dry basis })} \times 100
$$


The vitamin A result of each maize porridge sample was compared with its corresponding maize meal sample.

\subsection{Statistical Analysis}

Data was analyzed by Analysis of Variance (ANOVA), Pearson's correlation test and Principal Component Analysis (PCA), which were applied to determine and explain variation in the data. The data was analysed with SAS statistical software version 9.2 (SAS, 1999).

\section{Results and Discussion}

\subsection{Method performance}

Blake (2007) evaluated several official AOAC, CEN and ISO methods for the determination of fat soluble vitamins. These methods involve alkaline saponification of the test material to eliminate the fat without removing the fatsoluble vitamins, liberate natural retinol in the cells and to hydrolyse added vitamin A in fortified food products to retinol. After saponification, the vitamins are separated by liquid-liquid extractions with organic solvents. The organic phases are pooled and evaporate to dryness. This is then redissolved in the mobile phase and mostly analysed by liquid chromatography.

The performance of the method was determined as summarised in Table 1. Precision were assessed using the criteria developed by AOAC International (2005b). The calculated Horwitz Ratio (HorRat) of 1.28 for repeatability and 1.13 for reproducibility is consistent with the guideline range of $0.5-2.0$. Linearity was 
confirmed by least-squares regression analysis of the calibration standards. The UV-signals (peak height) were linear in the range $0-566 \mu \mathrm{g} / 100 \mathrm{ml}$ with an accepted linearity of $R^{2} \geq 0.98$. Accuracy was determined by two different interlaboratory studies as well as with a standard reference material. The values were compared and acceptable z-scores $(<2)$ obtained. The method was validated for linearity, repeatability, reproducibility, LOD, LOQ and accuracy.

Table 1: Limit of Detection (LOD), Limit of Quantification (LOQ) and Precision

\begin{tabular}{||c|c|c|ccc|ccc||}
\hline \hline & LOQ & LOD & \multicolumn{2}{|c|}{ Repeatability } & \multicolumn{3}{|c||}{ Reproducibility } \\
& $(\mu \mathrm{g} / 100 \mathrm{~g})$ & $(\mu \mathrm{g} / 100 \mathrm{~g})$ & Mean & SD & CV\% & Mean & SD & CV\% \\
All-trans & 20 & 7 & 0.536 & 0.057 & 10.593 & 0.588 & 0.082 & 14.017 \\
Vitamin A & & & & & & & & \\
\hline
\end{tabular}

\subsection{Vitamin A content of maize meal as purchased in supermarkets}

Vitamin A concentrations were evaluated for outliers using the Q-test. These values were excluded form the data set. The mean vitamin A content per brand can be seen in Figure 1. Brand $A$ had the highest mean vitamin $A$ concentration $(261 \mu \mathrm{gRE} / 100 \mathrm{~g})$, and is also the only brand analysed with a higher mean vitamin $A$ concentration than the regulatory requirement of $187.7 \mu \mathrm{g} / 100 \mathrm{~g}$ (Foodstuffs, Cosmetics and Disinfectants Act, 2003). Brand D had the lowest mean vitamin A concentration $(<19 \mu \mathrm{gRE} / 100 \mathrm{~g})$. According to fortification principles, the maize meal is fortified with protected and stabilised Vitamin A palmitate to improve stability of the added vitamin. The protected particles tend to be heterogeneously distributed throughout the maize meal, and this may influence 
the precision of the analyses (Blake, 2007). This may also cause segregation of the maize meal leading to a variation of vitamin A content within one brand of maize meal. This might explain the large variation in results within a specific maize meal brand. Although there is a regulatory requirement for vitamin $A$, a large variation in vitamin A content between different brands was observed. This variation might be an indication of poor quality control at the millers. Poor or variable quality of fortification premixes, unreliable and poorly fabricated equipment, and inadequate manufacturing and marketing facilities lead to poor product quality (Johnson, Mannar and Ranum; 2004).

Figure 1: Mean vitamin A concentration ( $\mu \mathrm{g} \mathrm{RE} / 100 \mathrm{~g}$ ) of different brands of maize meal as purchased in supermarkets in the Tshwane-metropole.

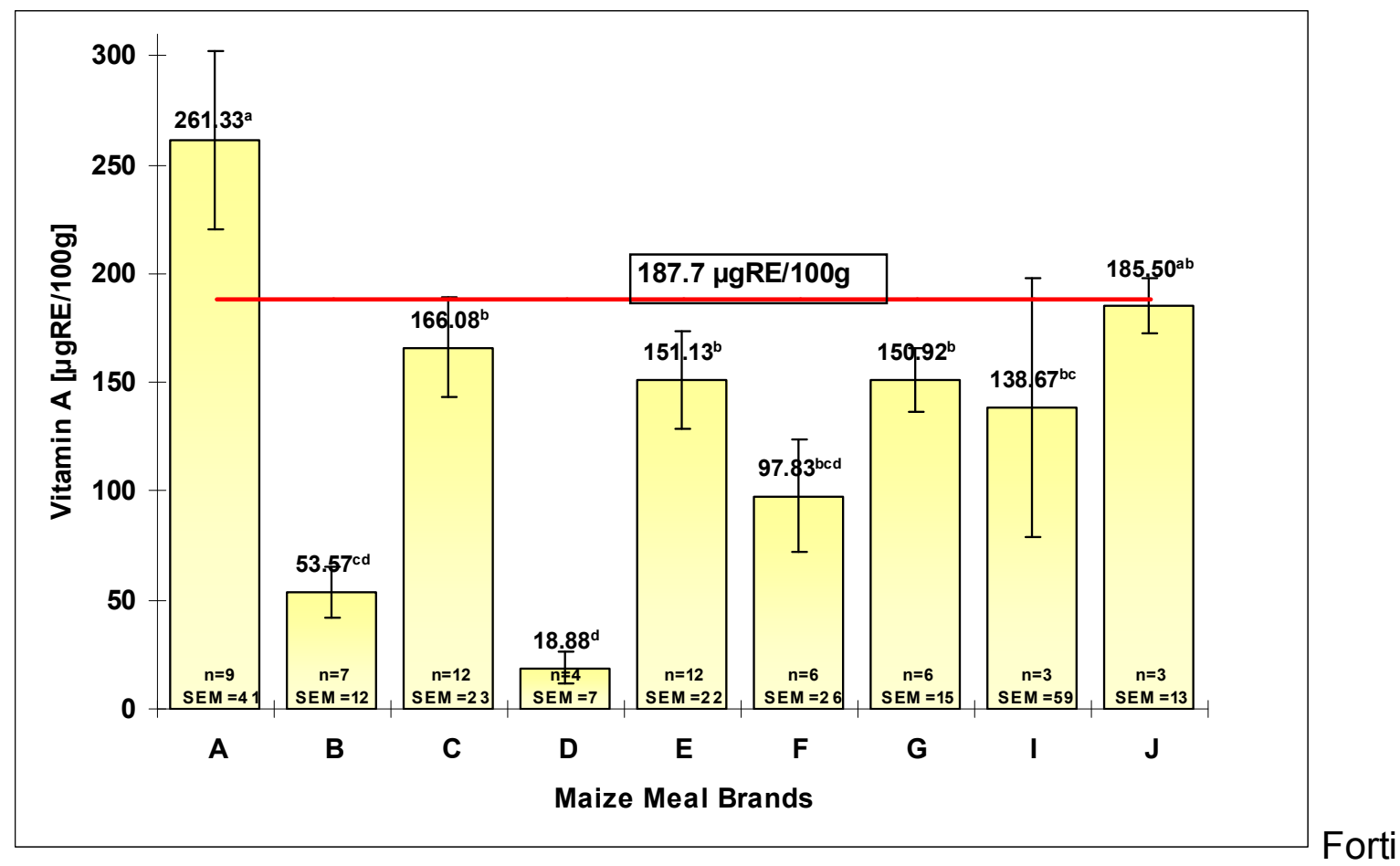

fication mixes supplied by unregistered suppliers and the stability of the vitamin $A$ are challenges identified by the South African Department of Health (de Hoop; 2010). Major obstacles to the implementation of an adequate food control system 
(FCS) occur when material sourcing, production, packaging, storage, transport conditions and delivery systems are sub-optimal. The lack of efficient and skilled manpower to carry out an effective FCS both at the production and the government levels, coupled with limited training opportunities is another major obstacle (Clarke, 1995). Moreover, legislation and regulation in South Africa may not be well developed. Enforcement mechanisms are probably not yet adequately developed and established to ensure that government standards are met.

\subsection{Vitamin A concentration of maize porridge}

Vitamin A and dry matter content were determined on each of the maize meal samples and the corresponding porridge samples. An average retention of $39.8 \%$ was observed. Results are shown in table 2.

The average cooking losses of vitamin $A$ in super maize meal according to the CSIR-report on the stability of fortified food vehicles for the National Food Fortification Programme was reported as 53\% (Kuyper, 2000). This relates to an average retention of $47 \%$. When the more recent nutrient composition values of super maize meal, as reported by Wolmarans, Danster and Chetty (2005) was used, retention of $39.5 \%$ was calculated for soft porridge, which compared favourably with results of this study. The result is best explained by the fact that vitamin $A$ is stable under inert atmosphere. However, it rapidly loses its activity when heated in the presence of oxygen (Lešková, Kubíová, Kováčiková, Košická, Porubská, and Holčíová, 2006).

A Pearson's correlation test (Table 3) and principal component analysis (PCA) was done to determine if there is a association between the retinol concentration and dry matter in the maize meal (raw) and the retinol concentration and dry 
Table 2: Vitamin A content ( $\mu \mathrm{gRE} / 100 \mathrm{~g}$ dry matter) of maize meal and maize porridge samples of seven different brands.

\begin{tabular}{|c|c|c|c|}
\hline \multirow[t]{2}{*}{ Brands } & $\begin{array}{c}\text { Maize Meal } \\
\text { (Raw) }\end{array}$ & $\begin{array}{c}\text { Maize Porridge } \\
\text { (Cooked) }\end{array}$ & \multirow[t]{2}{*}{$\%$ Retention of Vitamin A } \\
\hline & \multicolumn{2}{|c|}{ *Vitamin A ( $\mu \mathrm{gRE} /$ 100g DM) } & \\
\hline A & 174.7 & 85.5 & 48.9 \\
\hline B & 93.7 & 45.5 & 48.6 \\
\hline C & 238.8 & 83.9 & 35.1 \\
\hline D & 10.5 & 5.90 & 55.8 \\
\hline $\mathbf{E}$ & 237.8 & 45.3 & 19.0 \\
\hline G & 245.4 & 90.5 & 36.9 \\
\hline \multirow[t]{2}{*}{$\mathbf{J}$} & 201.6 & 69.1 & 34.3 \\
\hline & & Average retention & $39.8 \pm 12.3$ \\
\hline
\end{tabular}

*Vitamin values are reported on a dry weight basis.

matter in the maize porridge (cooked). The correlation between retinol and dry matter in the raw maize meal is not significant $(r=-0.525 ; p>0.05)$. This is expected as retinol is not related or dependant on the dry matter content. The correlation between the dry matter in the raw maize meal and in the cooked porridge is significant $(r=-0.542 ; p \leq 0.046)$. Although the dry matter in the raw maize meal and in cooked maize meal (porridge) is dependant on each other, it must be taken into account that the matrix of the maize meal change during cooking as water is absorbed and heating causes starch gelatinisation. As is expected the correlation between the retinol in the maize meal and in the maize porridge is high $(r=0.833 ; p \leq 0.000)$, but not equal to. This is supported by the retention values calculated and is an important consideration in determining 
fortification levels.

Table 3: Pearson Correlation matrix between retinol content and dry matter of the raw maize meal and retinol content and dry matter of the cooked maize porridge

\begin{tabular}{|c|c|c|c|c|}
\hline Variables & Raw-DM & Raw-Retinol & Cook-DM & $\begin{array}{l}\text { Cook- } \\
\text { Retinol }\end{array}$ \\
\hline Raw-DM & & $\begin{array}{c}-0.525 \\
(p>0.054)\end{array}$ & $\begin{array}{c}-0.542^{*} \\
(p \leq 0.046)\end{array}$ & $\begin{array}{c}-0.576^{*} \\
(p \leq 0.031)\end{array}$ \\
\hline Raw-Retinol & & & $\begin{array}{c}0.087 \\
(p>0.767)\end{array}$ & $\begin{array}{l}0.833^{* * *} \\
(p \leq 0.000)\end{array}$ \\
\hline Cook-DM & & & & $\begin{array}{c}-0.038 \\
(p>0.897)\end{array}$ \\
\hline
\end{tabular}

Significant levels: $\left.{ }^{*} p \leq 0.05 ;{ }^{* *} p \leq 0.01 ;{ }^{* *} p \leq 0.001\right)$

The PCA explained $77.71 \%$ of the variation in the data. See figure 2 on the biplot of retinol and dry matter (DM) in maize meal (raw) and maize porridge (cooked). On PCA1 (x-axis) $50.94 \%$ of the data was explained. The variables retinol-raw (31.38\%), DM-raw (-25.89\%) and retinol-cooked (23.98\%) contributed the most to the variation. On PCA2 (y-axis) $26.77 \%$ of the data was explained by the variables DM-cook (46.68\%) and retinol-cook (25.57\%). If the retinol in the raw and cooked samples were high then the dry matter was low.

To understand the contribution of the fortified maize meal on the vitamin A intake of children, the results of the different brands were translated into Recommended 
Figure 2: PCA Biplot of retinol and dry matter (DM) in maize meal (raw) and maize porridge (cooked).

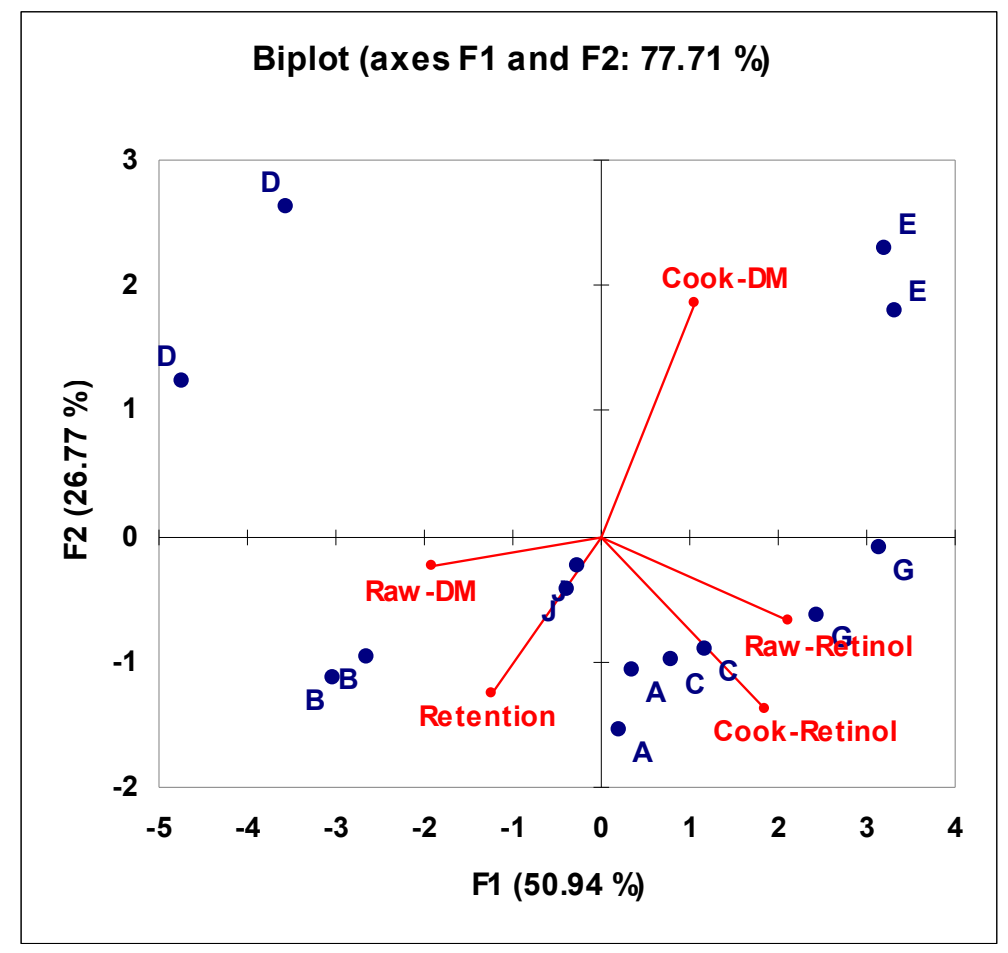

Dietary Allowance (RDA), Daily Recommended Intake (DRI) and Recommended Safe Intake (RSI) values (FAO; 2001). The RDA and DRI for children 1-3 years and $4-9$ years is 300 and $400 \mu \mathrm{g} /$ day respectively. The RSI values used by the FAO to correct VAD in a population are 400,450 and $500 \mu \mathrm{g} /$ day for children 1-3 years, 4-6 years and 7-9 years respectively. According to the National Food Consumption Survey (Steyn, Maunder and Labadarios, 2006) the average portion size reported for children 12-108 months (1-9 years), was $455 \mathrm{~g} /$ person/day for maize porridge. This portion size was used in the calculation of the average intake of vitamin A from soft maize porridge based on the concentration levels as determined in this study.

The highest contribution to the RDA and RSI was made by maize meal Brand $G$ and the lowest contribution by Brand D. On average, $17 \%$ of Recommended Dietary Allowance (RDA) for children 1-3 years and 13\% of RDA for children 4- 
Table 4: Vitamin A content ( $\mu \mathrm{gRE} / 100 \mathrm{~g}$ ) of maize meal and maize porridge samples of seven different brands and the contribution towards the Recommended Daily Allowances (RDAs) and Recommended Safe Intake (RSI) for 1-9 year old children

\begin{tabular}{|c|c|c|c|c|c|c|c|c|}
\hline Brands & $\begin{array}{r}\text { Maize Meal } \\
\text { Vitamin }\end{array}$ & $\begin{array}{l}\text { Maize Porridge } \\
\text { ugRE/100g) }\end{array}$ & $\begin{array}{c}\text { Vitamin A/portion size* } \\
(\mu g R E / 100 \mathrm{~g})\end{array}$ & $\begin{array}{c}\% \text { RDA }^{\#} \\
\text { (1-3 years) }\end{array}$ & $\begin{array}{c}\% \text { RDA }^{\#} \\
\text { (4-9 years) }\end{array}$ & $\begin{array}{c}\% \mathrm{RSI}^{\$} \\
\text { (1-3 years) }\end{array}$ & $\begin{array}{c}\% \mathrm{RSI}^{\$} \\
\text { (4-6 years) }\end{array}$ & $\begin{array}{c}\text { \% } \mathrm{RSI}^{\$} \\
\text { (7-9 years) }\end{array}$ \\
\hline $\mathbf{A}$ & 155 & 16 & 71 & 24 & 18 & 18 & 17 & 14 \\
\hline B & 83 & 8 & 34 & 11 & 8 & 8 & 7 & 7 \\
\hline C & 212 & 15 & 67 & 22 & 17 & 17 & 15 & 13 \\
\hline D & 9 & 1 & 5 & 2 & 1 & 1 & 1 & 1 \\
\hline $\mathbf{E}$ & 210 & 9 & 42 & 14 & 10 & 10 & 9 & 8 \\
\hline G & 217 & 18 & 80 & 27 & 20 & 20 & 18 & 16 \\
\hline \multirow[t]{2}{*}{$\mathbf{J}$} & 180 & 13 & 56 & 19 & 14 & 14 & 12 & 11 \\
\hline & & & Average contribution & $17 \pm 9$ & $13 \pm 6$ & $13 \pm 6$ & $11 \pm 6$ & $10 \pm 5$ \\
\hline
\end{tabular}

${ }^{*}$ Portion size: $455 \mathrm{~g} /$ person/day for maize porridge (Steyn, Maunder and Labadarios, (2006)

\#The RDA and DRI for children 1-3 years and 4-9 years is 300 and $400 \mu \mathrm{g} /$ day respectively.

${ }^{\$}$ The RSI values are 400,450 and $500^{\circ} \mu \mathrm{g}$ /day for children 1-3 years, 4-6 years and 7-9 years respectively. 
9 years old were met by the fortification of the maize meal (Table 3). Keeping in mind that this would be zero percentage if not fortified, but should be a $31 \%$ of RDA according to legislation. This contribution is even lower when looking at the Recommended Safe Intake levels using by the FAO. When using the same retention values as calculated in this study, the contribution to the RDA for children from maize meal that is fortified according to the minimum levels as stipulated in the regulations (ie. $187.7 \mu \mathrm{g}$ vitamin $\mathrm{A} / 100 \mathrm{~g}$ ) will only be $16 \%$ and $12 \%$ respectively. This is approximately half of the $31 \%$ government want to at least achieve through the mandatory fortification of maize meal (Foodstuffs, Cosmetics and Disinfectants Act, 2003).

In essence, food fortification can contribute to the improvement of the overall vitamin A status of children aged 1-9 years. This was also reported by Steyn, Nel and Labadarios (2008) in their analysis of dietary micronutrient intake pre- and post-fortification using existing dietary data. However, it is suggested that the level of vitamin A fortification is raised to at least achieve the $31 \%$ RDA contribution or even higher. A review by Allen and Haskell (2002) has indicated that the risk of excessive vitamin A consumption from fortified foods in women and young children is likely to be negligible.

\section{Conclusion}

The quantitative difference in the vitamin A content of fortified white maize meal as purchased and consumed is shown. Vitamin A concentrations varied from the highest concentration of $226 \mu \mathrm{gRE} / 100 \mathrm{~g}$ to the lowest concentration of $<19 \mu \mathrm{gRE} / 100 \mathrm{~g}$. Reasons for the large variation in vitamin A concentration might 
be explained by substandard premixes, inadequate mixing of the fortification premix into the maize meal, segregation of the fortificant and the maize meal, storage losses or poor quality control by the milling companies. The average retention of vitamin $\mathrm{A}$ in maize porridge was calculated as $39.8 \%$. The low retention observed might be an indication of poor stability of the vitamin $A$ fortificant under cooking conditions.

The lower than regulated concentration levels and the low retention of the vitamin A contribute towards the RDA for vitamin A not being met for 1-9 year old children. This might be an explanation of the results found during the National Food Consumption Survey Fortification Baseline Study (NFSC-FB-I) done during 2005. One of the main findings in this study is that the prevalence of poor vitamin $A$ status in children appears to have increased when compared with previous national data (NFSC-FB-I; 2008). This emphasise the need for an efficient food control system (FCS) in South Africa in order for food fortification processes to meet nutritional objectives. Evaluation of some of the more mature fortification programs, mainly in Latin America, suggests that the quality of vitamins, minerals and micronutrient premixes may be a barrier to achieving health and nutrition results (DSM; 2009). A consideration that should be high on the priority list of the overall micronutrient strategy is the adequate and efficient monitoring, evaluation, regulation and quality assurance of all premixes and maize meal.

Correcting VAD in populations at risk of deficiency is an investment in improving human development. Based on the results and evaluations of this study, it appears that fortification of maize meal can contribute to the micronutrient intake of children under nine years of age and improve the overall micronutrient density of their 
diets. It is necessary to take into account whether the efficacious nutrient supply can be met. The efficacious nutrient supply depends on the amount of vitamin Acontaining foods consumed, Vitamin A content of each food consumed, and bioefficacy of vitamin A in the food consumed (Van Lieshout and West, 2004). It is therefore important to also verify the vitamin A concentration in bread as this is the other food vehicle used for fortification and to evaluate the bioavailability of the added vitamin $\mathrm{A}$.

\section{Acknowledgements}

Sincere gratitude to Mrs Liesl Morey at the ARC-Biometry Unit for the statistical analyses and to the National Research Foundation for financial support under the focus area group of Prof Johann Kirsten, School of Agricultural and Food Science, University of Pretoria.

\section{References.}

Allen, LH. \& Haskell, M. (2002). Estimating the potential for vitamin A toxicity in women and young children. Journal of Nutrition 132(9), 2907S - $2919 S$.

AOAC, (2005a). Official methods of analysis of the Association of Official Analytical Chemists. In: Horwitz, W. (Ed.), Method 935.29, 18th ed. Association of Official Analytical Chemists, Gaithersburg, USA.

AOAC, (2005b). Official methods of analysis of the Association of Official Analytical Chemists. In: Horwitz, W. (Ed.), Appendix E: Laboratory quality assurance, 18th ed. Association of Official Analytical Chemists, Gaithersburg, USA. 
Bengtsson, A., Namutebi, A., Alminger, M.L., \& Svanberg, U. (2008). Effects of various traditional processing methods on the all-trans-ß-carotene content of orange fleshed sweet potato. Journal of Food Composition and Analysis, 21, 134 143.

Blake, C.J.B. (2007). Status of methodology for the determination of fat-soluble vitamins in foods, dietary supplements, and vitamin premixes. Journal of AOAC International 90(4), 897-910.

Clarke, R. (1995). Micronutrient fortification of food: Technology and Quality Control [Internet], In: FAO. (1996) Food Fortification: Technology and Quality Control. FAO Food and Nutrition Paper 60, reprinted 1997. Available from: <http://www.fao.org/docrep/W2840E/W2840E00.htm> [Accessed on 17 March 2005].

de Hoop, M. (2010). National Food Fortification Programme: Plans to revitalise the fortification programme. Nutrition Congress 2010, Durban International Convention Centre, 19-22 September. Presentation available from: http://www.nutritioncongress.co.za/images/stories/PDFS/Tuesday/Venue5B/16h35 \%20maude $\% 20$ de $\% 20$ hoop $\% 20$ tuesday $\% 20$ hall $\% 205 \mathrm{~b} \% 202 . p d f$.

DSM (2009). Quality is Essential. Published April 2009. DSM Nutritional Products LTD, Nutrition Improvement Program, PO Box 2676, CH-4002, Basel, Switzerland. FAO (2001). FAOMHO expert consultation on human vitamin and mineral requirements: Chapter 7; Food and Nutrition Division; Rome. 
Foodstuffs, Cosmetics and Disinfectants Act (2003) (Act no 54 of 1972), regulation R7634 dated 7 April 2003 on the fortification of certain foodstuffs as promulgated. Pretoria, Government Gazette.

Johnson, Q., Mannar, V. \& Ranum, P. (2004). Vitamin and Mineral Fortification of Wheat Flour [Internet], The Micronutrient Initiative Fortification Handbook.

Available from:

http://www.micronutrient.org/CMFiles/PubLib/Fort handbook1NDB-32420082608.pdf [Accessed 07 June 2010].

Kuyper, L. (ed). (2000). Report: Stability tests and sensory evaluation of fortified food vehicles for the national food fortification programme. Developed for The Directorate: Nutrition, Department of Health; Developed by: National Food Science and Technology Programme, BioChemtek, CSIR, Pretoria.

Lešková, E., Kubíová, J., Kováčiková, E., Košická, M., Porubská, J. \& Holčíová, K. (2006). Vitamin losses: Retention during heat treatment and continual changes expressed by mathematical models. Journal of Food Composition and Analysis $19,252-276$.

Long, G.L. \& Winefordner, J.D. (1983). Limit of detection. A closer look at the IUPAC definition. Analytical Chemistry 55(7), 712 - 724.

Markinor / Sunday Times Top Brands Results: Business-to-Consumer. (2008). $\begin{array}{llll}\text { Retrieved } & \text { September } & 15, & 2008\end{array}$ http://www.brandsandbranding.co.za/pdf/brandtrust.pdf 
Mehansho, H., Mellican, R.I.; Hughes, D.L., Compton, D.B. \& Walter, T. (2003). Multiple-micronutrient technology development and evaluation: from lab to market. Food and Nutrition Bulletin 24(4), pp. S111 - S119.

NFCS (National Food Consumption Survey) (2000). The National Food Consumption Survey: children aged 1-9 years South Africa, 1999, Department of Health, Nutrition Directorate, Pretoria, South Africa.

NFCS-FB-I (National Food Consumption Survey Fortification Baseline) (2008). Excutive Summary of the National Food Consumption Survey Fortification Baseline South Africa, 2005. South African Journal of Clinical Nutrition 21(3) (Supplement 2), 245-300.

SAVACG (South African Vitamin A Consultative Group) (1996). Anthropometric, vitamin $A$, iron, and immunisation coverage status in children aged $6-71$ months in South Africa, 1994. South African Medical Journal 86, 354-357.

Steyn, N.P., Maunder, E.M., Labadarios, D. \& Nel, J.H. (2006). Foods and beverages that make a significant contribution to macro- and micronutrient intakes of children in South Africa: Do they meet the food-based dietary guidelines? South African Journal of Clinical Nutrition 19(2), pp. 66-76.

Steyn, N.P., Nel, J. \& Labadarios, D. (2008). Will fortification of staple foods make a difference to the dietary intake of South African children? South African Journal of Clinical Nutrition 21(1), 22-26.

Van Lieshout, M. \& West, C.E. (2004). Chapter 2: Vitamin A. In: Micronutrient Malnutrition Course for Southern Africa, September 6 - 17, 2004; University of Pretoria, South Africa. pp. 1-29. 
WHO (World Health Organisation) (2006). Guidelines on food fortification with micronutrients/ edited by Allen, L, de Benoist, B, Dary, O, \& Hurrell, R, Part III: Fortificants - physical characteristics, selection and use with specific food vehicles. ISBN 924159401 2. Geneva, World Health Organization.

WHO (World Health Organisation) (2009a). Global prevalence of vitamin A deficiency in populations at risk 1995-2005. WHO Global Database on Vitamin A Deficiency. Geneva, World Health Organization.

WHO (World Health Organisation) (2009b). Recommendations on wheat and maize flour fortification meeting report: Interim consensus statement. Geneva, World Health Organization. Retrieved May 31, 2010 from: http://www.who.int/nutrition/publications/micronutrients/wheat maize fort.pdf

Wolmarans, P., Danster, N. \& Chetty, J. (2005). Energy and nutrient composition of South African maize meal. Technical report. Tygerberg: Nutritional Intervention Research Unit, South African Medical Research Council. 